REVISTA

dela

CEPA

NUMERO EO

ACOBTO 1993

SANTIAGO DE CHILE

ANIBAL PINTO

Director

EUGENIO LAHERA

Secretario Técnico

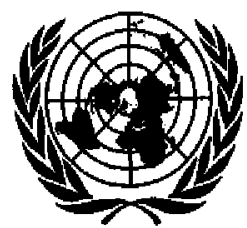

NACIONES UNIDAS 
Jacobo Schatan

La Integración reglonal en los años noventa

Gert Rosenthal

El resurgImiento de la Integración y el legado de Prebisch

José Manuel Salazar

La liberallzación comerclal en América Latına

Manuel Agosin y Ricardo Ffrench-Davis

Crecimiento, crisls y viraje estratéglco

Joseph Ramos

Falla del mercado y política tecnológlca

Jorge M. Katz

Crisis monetarla, dolarlzación y tipo de camblo

Paulo Nogueira Batista Jr.

El financiamlento en los procesos de descentralización

Dolores Marta Rufián Lizana

Migración intrarregional de mano de obra calificada

Jorge Martinez

Clencias sociales y realidad soclal en Centroamérlca

Andrés Pérez

Formación histórlca de la estratificación soclal en América Latina

Enzo Falefto

Estructura socioeconómica y comportamlento colectivo

Rodrigo Baño

Clasiflcaclón por autores y temática de los artículos publicados

en la Revista de la CEPAL, del número 1 al 50

Orlentaciones para los colaboradores de la Revista de la CEPAL 


\section{Estructura socioeconómica y comportamiento colectivo}

\section{Rodrigo Baño}

Profesor del Departamento de Sociologla de la Universidad de Chile y profesor investigador de la Facultad Latinoamericana de Ciencias Sociales (FLACSO) - Chile.
Este artículo pasa revista a diversas modificaciones en la economía regional y su efecto en la estratificación social, y analiza las posibilidades de acción política de los distintos sectores sociales. Diversas transformaciones en el terreno económico han modificado la tradicional heterogeneidad de la economia latinoamericana y la significación relativa de los distintos sectores de la economfa, lo que se refleja, por ejemplo, en la nueva importancia de la agroindustria y la penetración recíproca del sector de los servicios y el sector productivo. Actualmente se acepta una diferenciación genérica entre grupos sociales "incorporados" y "excluidos", pero estas categorfas no sólo carecen de precisión y homogeneidad, sino que también subestiman las relaciones reales entre ellas: por ejemplo, las que se dan con frecuencia entre el sector formal y el informal mediante la subcontratación. Al modificarse la heterogeneidad de la economía regional nuevos sectores podrían influir en los procesos sociales y políticos, lo que pone sobre el tapete la necesidad de revisar las condiciones de la acción colectiva dadas por la capacidad de generalizar y organizar intereses comunes, sea para la defensa corporativa o para la proyeccion de esos intereses como propuesta de orden social. 


\section{I}

\section{Los rasgos actuales de la estructura económica}

\section{y la estructura social}

La heterogeneidad estructural de las economías latinoamericanas es un rasgo permanente de ellas, pero las transformaciones del proceso económico han ido modificando el tipo de heterogeneidad e introduciendo cambios de particular relevancia en la estratificación social. Por cierto que podría postularse una distinción burda entre "incorporados" y "excluidos". No obstante, habría que definir bien ambas categorías, puesto que los que "participan" no por eso dejan de tener fuertes diferencias entre sí, y los "excluidos" tampoco forman una categoría homogenea. Lo importante es la existencia de relaciones significativas entre ambos sectores, puesto que no se trata de categorías que funcionen en sistemas diversos sin vincularse entre sí. En términos concretos: la exclusión tiende a asociarse con la pertenencia al denominado sector informal, pero las personas que se inscriben en el sector informal, por el tipo de relaciones de trabajo que establecen -contratos precarios, ausencia de prestaciones sociales, carencia de organización-, suelen incorporarse a actividades catalogadas como modernas o formales a través de la subcontratación. Así sucede, por ejemplo, con los "vendedores ambulantes", que de hecho distribuyen productos incluso de empresas transnacionales. El uso de categorías como las de "incorporados" y "excluidos" debería ser objeto de precisiones, ya que presenta un problema de orden teórico similar al que se plantea cuando se postula la existencia de un "dualismo estructural". Es necesario, entonces, precisar las diferencias entre ambas, la índole de las relaciones entre ellas y los mutuos condicionamientos y la dinámica de esas relaciones.

Cabe tener en cuenta también el cambio de las relaciones entre las diversas actividades económicas: la industria, el agro, los servicios. La clásica distribución entre sector primario, secundario y terciario llevaba muchas veces aparejada la idea de

El presente artículo se basa en un trabajo sobre "Estructura social y estilo de desarrollo en América Latina", preparado en conjunto con Enzo Faletto para la División de Desarrollo Social de la CEPAL. una cierta secuencia en el desarrollo de cada uno de ellos. En America Latina se estimó a menudo que la evolución de la economía se apartaba en ocasiones de este patrón de crecimiento, y que esto implicaba distorsiones en su estructura y estratificación sociales. El hecho es que el cambio de las relaciones entre esos distintos sectores ha modificado marcadamente, por ejemplo, la importancia de la actividad agroindustrial o el significado de la penetración recíproca de los servicios y del sector productivo, principalmente en rubros como el financiamiento, la comercialización, y más recientemente, las comunicaciones y la informática. En la región las deficiencias de las conexiones entre los sectores son todavía apreciables; pero cuando ha existido interconexión ha habido también cambios en la estratificación social que no encajan en las viejas clasificaciones. En lo que sigue se intentará mostrar -por cierto de modo muy general - algunos de los problemas esbozados, para contribuir a la reflexión futura sobre las nuevas características de la estructura y la estratificación sociales. Un punto de partida adecuado para el análisis de la relación entre los sectores económicos y la estructura social es el trabajo de Rubén Katzman sobre las transformaciones sectoriales del empleo en América Latina (Katzman, 1984).

\section{El sector Industrlal}

Son varios los autores que se han preocupado de definir los tipos de organización industrial existentes. Por ejemplo, Touraine (1989) señala que en muchos países se distinguen cuatro niveles de organización industrial: las industrias dominantes, que a menudo son extractivas y que a veces representan más de la mitad de las exportaciones del país (el cobre en Chile, el estaño en Bolivia, el petroleo en Venezuela y Ecuador); la gran industria moderna, cuyo capital en la mayoría de los casos es público o extranjero; la industria nacional y de la construcción, dominada por el capital nacional privado, y el sector informal, formado por pequefias unidades de baja productividad. Otros autores distinguen entre las empresas fundamentalmente por su ta- 
maño (grandes, medianas, pequeñas y microempresas); por su tipo de producción (productos básicos, bienes de capital, bienes de consumo durables, bienes de consumo no durables), o de acuerdo con muchos otros criterios. Por cierto, cada una de estas clasificaciones está vinculada al propósito específico de la investigación de que se trate. Las diferentes modalidades de clasificación de las empresas no están ajenas a los estudios de estratificación social, ya que las más de las veces quienes llevan a cabo esos estudios tienen que atenerse a las clasificaciones existentes. Cabe reconocer que si el rasgo decisivo de la estratificación en América Latina es la heterogeneidad social derivada de una estructura económica heterogénea, no resulta indiferente el modo en que se dé cuenta de tal diferenciación.

Quizás si lo primero que ha de tenerse en cuenta es el tantas veces mencionado patrón imitativo del consumo y de las estructuras de ciertos segmentos productivos. Fajnzylber (1983) señalaba una afinidad morfológica de la industrialización latinoamericana con la de los países avanzados: el crecimiento industrial latinoamericano había sido muy rápido -incluso superior al de ciertos niveles de paises avanzados-, la modificación de la estructura sectorial estaba en armonía con la observada en esos países, y el incremento de la productividad era alto y estaba asociado a los sectores más dinámicos. Sin embargo, esta similitud de una parte importante del sector industrial de la región con los países avanzados no se daba en la base productiva del conjunto de la economía, sino que privilegiaba las actividades o rubros productivos capaces de encontrar su espacio en el mercado internacional.

$\mathrm{Si}$ observamos el panorama actual, vemos que en algunos casos el sector industrial ha establecido estrechas vinculaciones con otros sectores, pero éstas no son tan generalizadas ni tan positivas como sería de desear: por ejemplo, si se examina la relación de la industria con el sector agrícola se observa que la mayor parte de la maquinaria agraria, los pesticidas, los fertilizantes y otros insumos de origen industrial es importada y que, por lo general, la industria no ha sido capaz de aprovechar plenamente el mercado potencial constituido por la agricultura. Es importante anotar que, de existir vinculaciones entre la industria y el agro, las distorsiones del patrón productivo de la primera se trasladan al segundo e influyen en las formas de estratificación social que, como se ha dicho, están asociadas a la heterogeneidad estructural. Por otra parte, es dudoso que el patrón industrial vigente, aunque logre ampliar sus vinculaciones con el agro, pueda modificar este último sector en su conjunto. Puesto que la expansión del sector industrial se ha debido más a la incorporación de nuevos productos que a una mayor escala de producción de los bienes existentes, se confirmaría la idea de que el aumento de la producción apunta de preferencia a la intensificación del consumo de los grupos sociales medios y altos.

Algo similar sucede en la relación del sector industrial con el de los servicios (por ejemplo, en el ámbito financiero). Las actividades en que predominan las empresas transnacionales son generalmente las que exhiben mayor dinamismo, y una gran capacidad de obtener respaldo externo y una rentabilidad alta. No es extraño entonces que atraigan más a las colocaciones del sector financiero, inclusive del interno. Merece destacarse que una proporción creciente del financiamiento de las empresas transnacionales proviene de fuentes financieras del país receptor.

Otro hecho significativo es la articulacion de grandes empresas, entre otras modalidades, mediante la constitución de grandes conglomerados económicos (holdings). De Oliveira (1989) seffala que el complejo petroquímico brasileño de Bahía ilustra esa forma de articulación: el conglomerado en ese caso posee acciones de 13 empresas, participa directamente en la gestión de 10 empresas en operación y siete en fase de implantación, e indirectamente en la de 18 empresas en el campo de la química, la petroquímica, la alcoholquímica y los fármacos.

En muchos otros países se han constituido también grandes conglomerados económicos, cuya base de acumulación ya no se encuentra principalmente en el sector financiero - como sucedió en un momento no muy lejano- sino en la producción de bienes transables en el mercado internacional (agrícolas, mineros e industriales). En estos conglomerados a menudo hay fuerte participación de capital transnacional. Pero la participación externa va más allá. De Oliveira (1989) señala que casi no hay sector ni empresa grande brasilefia que no explote alguna patente, marca, tecnología o proceso productivo extranjero. Además, hay mucho capital extranjero en la producción de bienes de consumo durables.

La presencia de empresas extranjeras no es un fenómeno específico de América Latina (Fajnzylber, 1983). Pero sí lo sería la magnitud de esa presencia, sus estructuras de produccion imitativas y el haberse aceptado su incorporación a actividades que no son necesariamente de alta complejidad tecnologica. Al 
respecto, extraña la omisión en la definición de políticas de los grupos internos que pueden influir en la acción pública, y el comportamiento del empresariado nacional, tanto público como privado.

La relativa ausencia de iniciativa local en estos planos es particularmente visible en las decisiones respecto a las opciones tecnologicas disponibles. Los empresarios se rigen fundamentalmente por criterios de racionalidad microeconómica, de manera que las técnicas que se seleccionan son similares a las empleadas por las empresas que lideran y orientan la expansión industrial. Como por lo común estas son las empresas transnacionales, el perfil tecnológico que termina imponiéndose corresponde más a los objetivos de crecimiento y diversificación de tales empresas que a objetivos macroeconómicos como, por ejemplo, la expansión del empleo a largo plazo. A menudo la evolución de las empresas transnacionales no va a parejas con la del conjunto de la estructura productiva del país receptor: no sólo suelen crecer más que sus similares nacionales, sino que el tipo de producción propio de estas empresas se expande con más rapidez que el de las producciones nacionales para el mercado interno. La heterogeneidad, que determina fuertes desigualdades en la estructura y estratificación sociales, tiende a acentuarse por esta vía.

Se suele creer que las empresas grandes son modernas y utilizan tecnología avanzada, en tanto que las empresas pequeñas son tradicionales. Sin embargo, sucede a veces que las grandes empresas emplean tecnologías tradicionales y las pequefias empresas hacen uso de tecnologías avanzadas. Por otra parte, la modernidad de las empresas no se mide sólo por la tecnología que usan, pensada en términos de maquinaria y equipo productivo, sino que también por la forma de organizar su producción, el dinamismo de las relaciones que instauran en el ámbito económico y el papel que desempeñan en el desarrollo industrial.

Si se acepta lo anterior, cabe suponer que las industrias de bienes de capital son las que tienen mayor capacidad de transmitir y difundir el desarrollo tecnologico y, por lo tanto, que la debilidad observada en el ámbito tecnologico latinoamericano se asocia al atraso de esta rama industrial.

Para clasificar las empresas industriales se han utilizado diversos criterios. Uno de estos es el del tamaño de la empresa, medido por el número de personas que ella ocupa. Este criterio implica no sólo una diferencia numérica, sino que también distintos niveles de complejidad funcional y diferentes formas de organización y de propiedad. Cada uno de los gru- pos que componen la empresa - propietarios, empresarios, personal directivo, personal administrativo, distintos tipos de obreros- establece un conjunto de relaciones que lo diferencia de grupos similares en otro tipo de empresas. Esto redunda en una mayor heterogeneidad y repercute en la estratificación social y el comportamiento de los distintos grupos.

Basándose en dicho criterio, Castillo y Cortellese (1988) usan las siguientes definiciones, referidas a América Latina:

i) La gran empresa es aquella que ocupa más de 100 personas, exhibe una estructura industrial a escala relativamente alta, tiene una organización funcional diversificada en unidades específicas (por ejemplo, de gestión (de distintos tipos), administración, finanzas, ventas, producción, mantención, desarrollo, etc.); basa su organización laboral en la división del trabajo $\mathrm{y}$, en términos de propiedad, su estructura generalmente es compleja; su estrategia tiende al oligopolio y la competencia imperfecta, y proyecta su actividad no sólo a los mercados nacionales sino que también a los internacionales.

ii) La mediana empresa ocupa entre 50 y 99 personas; como estrategia busca elevar la escala de producción y ampliar los mercados; en ella las funciones directivas son ejercidas comúnmente por más de una persona, la organización es menos compleja que en las grandes empresas aunque mayor que en las pequenas, y se tiende a conservar cierto grado de flexibilidad productiva.

iii) La pequeña empresa ocupa entre 10 y 19 personas. En ella la propiedad es predominantemente individual o de sociedad simple y por lo común el propietario asume toda o gran parte de las actividades de gestion; la relación capital-trabajo es baja, lo que puede variar según el rubro de producción; la flexibilidad tecnológica es elevada; los mercados de ventas son proximos, aunque hay excepciones, y generalmente el objetivo no es una opción de crecimiento que traiga consigo una organización más compleja y una mayor escala de producción.

iv) La "empresa informal" tiene una organización rudimentaria, sin una clara división del trabajo ni de la propiedad de los medios de producción, compromete muy poco capital y requiere pocas habilidades.

La participación de cada uno de estos tipos de empresas en el empleo industrial total varía de un país a otro.

Respecto a la condición en que se encuentran los obreros industriales, Wolfe (1990) anota que en los años ochenta éstos sufrieron conmociones aún más 
graves que las que afectaron a los asalariados de los estratos medios. Se combinó para producir tales efectos la pérdida material de ingresos y de capacidad de consumo con una alta inseguridad respecto al lugar que les correspondía en la sociedad y a sus perspectivas futuras. La reducción de sus salarios reales llegó en algunos casos hasta a 50\%, y en determinados momentos hubo tendencias al estancamiento e incluso a la declinación del número de obreros en las industrias, mientras la fuerza de trabajo urbana no cesaba de crecer. Los distintos sectores industriales y tipos de empresas exhibieton diferencias importantes no sólo de salarios, sino que también en las condiciones de trabajo, las relaciones laborales, la participación en los beneficios legales y el acceso a los diversos sistemas de seguridad y asistencia social.

La mayoría de los investigadores que han estudiado el movimiento obrero y el sindicalismo han señalado como factores de diferenciación entre los obrero sus grados de calificación y especialización, que muchas veces están estrechamente asociados al tipo de industria en que laboran; pero también son factores decisivos de esa diferenciación la naturaleza de la empresa en que trabajan (por ejemplo, el hecho de que sea transnacional, oligopólica, con mayor o menor grado de complejidad organizacional, etc.). Estas dos fuentes de diferenciación dan origen a orientaciones del movimiento obrero y formas de acción del movimiento sindical que difieren fuertemente entre sí. No obstante, en términos generales, Wolfe (1990) subraya que en los años ochenta decayó la capacidad de la mayoría de los sindicatos de proteger los intereses de sus afiliados, y que su capacidad de influir en los lineamientos de una política nacional quedó muy disminuida.

\section{El sector agrarlo}

En América Latina la población rural se ha convertido en una minoría, aunque en general se mantiene en números absolutos. Está más integrada que antes en las sociedades y economías nacionales, pero esta integración se ha producido generalmente en términos muy desventajosos y no ha sido completa (Wolfe, 1990).

López Cordovez (1982) indica que la importancia de la agricultura difiere de un país a otro, yendo de destacada a discreta. No obstante apunta que, según las cuentas nacionales, entre 1970 y 1980 el producto interno bruto agrícola de la región crecí $3.5 \%$ por año, frente a la cifra de $5.6 \%$ registrada para el PIB total. En ese mismo período la participación de la agricultura en el PIB total bajo de $14 \%$ a $11.4 \%$, y la participación de la fuerza de trabajo agrícola en la total disminuyo del $42.1 \%$ al $36.2 \%$. Este decrecimiento se dio junto con varias insuficiencias que el autor citado señala: i) respecto de la demanda alimentaria potencial de sociedades latinoamericanas con alrededor de 4.5 millones de mal nutridos (la producción alimentaria creció $0.8 \%$ por año mientras que la demanda efectiva subio $3.6 \%$ por año); ii) respecto del potencial productivo del agro en la región, ya que sólo se utilizó algo más que la cuarta parte de la superficie agrícola cultivable; iii) respecto de las exigencias de la exportación agrícola, y iv) respecto de la intensidad del crecimiento productivo.

La desigualdad social en el sector agrario ha seguido siendo un hecho preocupante. La FAO calculaba que en 1973 el $70 \%$ de la población agricola latinoamericana vivía en condiciones de subsistencia, que 45 millones de asalariados agrícolas y 40 millones de pequeños propietarios percibían en conjunto alrededor del 35\% del ingreso agrícola total, y que su ingreso medio per cápita se estimaba en 115 dólares de 1970 por año. Los agricultores medianos eran el $28 \%$ de la población agrícola y constituían el $43 \%$ de la empresas del sector. Los grandes propietarios representaban el $2 \%$ de la población agrícola, poseían el $22 \%$ de las empresas y su ingreso medio per cápita se estimaba en 2.560 đólares de 1970 por año. A lo anterior se sumaba una aún fuerte concentración del acceso a las tierras: los grandes propietarios ocupaban el $47 \%$ de las tierras bajo cultivo, y los campesinos sólo el $2.5 \%$ de ellas.

Si se distingue entre agricultura empresarial y agricultura de pequeños agricultores, a comienzos de los años setenta las diferencias entre ambas eran significativas.

El hecho es que los últimos decenios han estado marcados en América Latina por la descomposición de la agricultura tradicional. Según Gomes y Pérez (1979), frente a esta situacion surgieron tres opciones, que se han aplicado en combinaciones diversas en los distintos países: el aumento del número y la participación de los asalariados en la población activa agrícola; la expansión física de las agriculturas de subsistencia, aunque a veces sólo en términos de personas y unidades de producción, y el incremento de la migración a las ciudades. Pero a la vez la economía agraria de tipo capitalista fue adquiriendo un notorio predominio. El resto de alguna manera pasó a depender de ella: en el caso del minifundio, por la venta ocasional 
de fuerza de trabajo; en el caso de los campesinos autónomos, porque debieron colocar la parte del excedente que producían en un mercado donde la incidencia de la economía capitalista agraria era decisiva; y en el caso del latifundio, por la necesidad de reestructurar sus relaciones internas de producción para seguir participando competitivamente en el mercado. $\mathrm{Al}$ respecto, Miró y Rodríguez (1982) advierten que no ha habido procesos de homogeneización progresiva en el agro de la región, y que la incidencia en éste de la economía capitalista se manifiesta en ciertas zonas y espacios geográficos, y en otras no.

Por su parte, Gomes y Pérez (1979) consideran que la articulación de la economía campesina con la agricultura moderna se lleva a cabo también a través de las empresas comerciales y agroindustriales, las que se desarrollan conjuntamente con la capacidad de expandir la producción comercial del agro. Tales empresas tienden a un manejo monopsónico del mercado, lo que constituye un elemento adicional de captación del excedente producido por el sector campesino; este, en tanto, es el que suele absorber los efectos de las variaciones de precios y crisis de sobreproducción que pueden generarse.

Lopez Cordovez (1982) señala una serie de rasgos que caracterizan al sector empresarial agrícola moderno: mayor homogeneidad como segmento productor; empresas con un tamaño económico de mediano a grande; grado importante de control de los recursos productivos; cierta magnitud de capital y determinada composición de sus inversiones; relativa complejidad de los sistemas tecnológicos que adopta; algún grado de especialización en las líneas de producción; perfeccionamiento de la organización técnica y administrativa; instauración de ciertas modalidades de relación laboral; interrelación con otros ámbitos (como las finanzas, la industria, el comercio y los medios de comunicación) y vínculos con los centros de poder y decisión. Además, como indican Gomes y Pérez (1979), las empresas modernas son las que más a menudo se benefician de las inversiones públicas en infraestructura y de muchos de los incentivos económicos y servicios de apoyo, así como del acceso a créditos, precios remuneradores, mercados relativamente protegidos y asistencia técnica. Todo esto hace que las nuevas tecnologías tiendan a concentrarse en empresas de este tipo y que los grupos empresarios modernos tiendan a consolidarse. A lo anterior debe sumarse la capacidad política de estos grupos para movilizar el apoyo del aparato estatal.

En la modernización han participado también las empresas transnacionales, no sólo en actividades agrarias tradicionales sino también en la creación de una agroindustria. Aunque la agroindustria tiene cierta antigüedad en la región y de hecho el sector alimentario es uno de los más importantes de la industria regional, se repite en ella cierto patrón de la estructura productiva industrial. También en el agro las ramas que producen bienes de consumo populares crecen más lentamente que las que producen alimentos elaborados para estratos medios y altos.

López Cordovez (1982) seffala que en su expansión la agroindustria se apoya principalmente en el empresariado agrícola, que puede facilitarle la articulación de sus producciones con la actividad comercial. Por lo tanto, las empresas agrícolas orientan su produccion hacia los consumidores urbanos de ingresos medios y altos con capacidad economica suficiente para adquirir sus productos elaborados industrialmente. La agroindustria — señala el autor citado- deja de lado a la agricultura campesina y a los consumidores rurales y urbanos pobres. Pero las empresas transnacionales no sólo han estado presentes en el desarrollo de la agroindustria, ya que ha habido también una fuerte inversión extranjera en las industrias de la maquinaria agrícola, los productos agroquímicos (fertilizantes, insecticidas, fungicidas, herbicidas) y los productos veterinarios.

Estrechamente ligada a la transformación descrita del sector agrario se ha producido una "asalarización" de la fuerza de trabajo agrícola. Pero esta asalarización no siempre ha significado trabajo permanente. Una modalidad de contratación bastante extendida es la de los trabajadores temporeros, procedimiento común en Argentina y Chile para la recolección y empaque de frutas, $y$ en Centroamérica para la cosecha del café, pero que se extiende también a otras actividades. En Brasil se estima que aproximadamente el $40 \%$ de la fuerza de trabajo agrícola está contratada bajo dicho régimen. Según Katzman (1984), este fenómeno se ha asociado con la introducción parcial de tecnología ahorradora de fuerza de trabajo en ciertas fases del ciclo productivo de cada cultivo y también con la sobreoferta de fuerza de trabajo. En algunos casos la mano de obra para faenas temporales se recluta incluso en áreas urbanas y aun entre habitantes periféricos de las grandes metrópolis. Para Miro y Rodríguez (1982), la contratación de trabajadores temporales que reemplazan a los permanentes se asocia a la sobreoferta de trabajo; en cambio, cuando esta no existe o hay alternativas como la migración a zonas de frontera, se tiende a recrear relaciones simi- 
lares al colonato o directamente semiserviles. La contratación temporal tendría lugar incluso en zonas donde operan empresas agroindustriales, pero con escasez relativa de fuetza de trabajo.

Paradojicamente, junto al desarrollo de la economía agrícola empresarial se ha dado un aumento de las unidades familiares de explotación. Este fenómeno de "campesinización" ha sido bastante extendido en los países del área andina (Bolivia, Chile, Ecuador y Perú) pero también está tomando presencia, por ejemplo, en Centroamérica. Los especialistas en el sector agrario estiman que la agricultura campesina se caracteriza porque las motivaciones fundamentales de su actividad económica son las de asegurar el nivel de ingreso familiar, reproducir su fuerza de trabajo y reponer sus herramientas y aperos de labranza. La organización de sus labores productivas se asienta en el trabajo de la familia y lo que busca principalmente es la reproducción simple o ampliada de la unidad familiar. Sin embargo este campesinado no puede ser considerado meramente como la permanencia de una actividad tradicional.

En los momentos de crisis de comienzos de los años ochenta la agricultura campesina tuvo una capacidad de respuesta a veces superior a la de la economía empresarial, y contribuyo a que la caída de la producción de bienes básicos no fuera tan drástica como la esperada. Como hecho esporádico, incluso ha habido algunos grupos de pequeños terratenientes que han logrado beneficiarse de una mejor relación de precios de intercambio para los productos alimenticios en el mercado interno y a la vez acceder a un mayor apoyo estatal orientado a la agricultura campesina. Sin embargo, como la meta principal de la economía campesina sigue siendo la de asegurar la sobrevivencia del grupo familiar, en las nuevas condiciones el campesinado dedica parte de su tiempo de trabajo a faenas asalariadas en unidades productivas distintas de la unidad familiar. Los ingresos que así obtiene se han convertido en un elemento básico para la subsistencia de la familia y de la propia economía campesina.

\section{El sector de los servlcios}

La evolución del sector de los servicios y su significado es un tema que se discute hoy en América Latina. Comparado con la experiencia de países avanzados, el crecimiento del sector no parecía guardar relación con el grado de desarrollo de los sectores directamente productivos. En 1980 la participación de los servicios en la economía latinoamericana en su conjunto era semejante a la que se observaba en las economías centrales capitalistas en 1960, y en países como Argentina, Colombia, Chile, Uruguay y Venezuela la cifra era igual o superior a la de 1980 en las economías con que se comparaba (Pinto, 1984). Sin desconocer este hecho, otros autores han indicado que ha habido un cambio en el modo de considerar el sector de los servicios. Según ellos, el desarrollo fue concebido tradicionalmente como un proceso que se daba por etapas y pasaba paulatinamente de la agricultura a la industrialización y de ahí a una fase posindustrial, a veces denominada "sociedad de servicios".

Por su parte, Prieto (1986) hace notar que algunos estudios posteriores han asignado especial importancia a las conexiones que parecen existir entre determinadas actividades de servicios y el resto de la trama económica y social de los países. Las externalidades que generarían estas conexiones serían de tal magnitud, que no sólo transformarían el suministro eficiente y a bajo costo de ciertos servicios en uno de los factores condicionantes del ritmo de desarrollo, sino también en un elemento determinante para moldear los estilos y patrones de desarrollo buscados por los países. Lo anterior parece aplicarse a la fase actual del desarrollo de la economía internacional, aunque es preciso determinar cuáles servicios desempeñan el papel que se señala y cuáles no lo hacen y por lo tanto pertenecen más bien a lo que se ha dado en llamar la "terciarización espuria". El mismo autor destaca la magnitud del sector de los servicios en América Latina y su incidencia económica, social y tecnológica; en promedio este sector aporta alrededor del $60 \%$ del valor agregado total de la región y emplea por lo menos $46 \%$ de su fuerza de trabajo, cifra esta última que puede ser aún mayor si se tiene en cuenta la densidad laboral y el peso de las actividades de servicio en el extenso sector informal de las economías de la región. Esta última frase, sin desdeñar la significación del sector de los servicios, introduce un elemento de cautela acerca de su papel. Por su parte Pinto (1984), sin desconocer las modernizaciones que se han dado en el sector, subraya que en América Latina ha habido y hay un sobredimensionamiento de las ciudades principales que se asocia a una terciarización espuria, sobre todo en los servicios no calificados o en diversas modalidades de subempleo u ocupaciones informales.

Lo expuesto tiene gran relevancia para la consideracion de la naturaleza de la estructura y la estratificación sociales en América Latina y sobre todo para la comprensión de su dinámica de cambio y transfor- 
macion. Conviene entonces hacer algunas precisiones, aunque sólo sea a título ilustrativo. Katzman (1984) dice que estudios hechos en cinco países (Brasil, Costa Rica, Guatemala Perú y Venezuela), a comienzos de los años ochenta muestran que los servicios que más crecen son los vinculados a la producción (bancos, agencias de crédito, instituciones financieras, de seguros, de bienes raíces, servicios de almacenamiento y servicios generales a las empresas), pero que su participación en el sector es sólo de $7 \%$. El segundo lugar lo ocupan los servicios sociales y comunales, incluyendo las actividades de gobierno, las fuerzas armadas, la salud, la educación, la cultura, el bienestar social, las comunicaciones, el saneamiento urbano y otros servicios que en gran parte se prestan a través del aparato estatal. Los servicios distributivos (transporte y comercio) se hallan en tercer lugar en cuanto a tasa de crecimiento (salvo en Brasil), pero en cambio emplean el grueso de la fuerza de trabajo del sector terciario. Por último, el cuarto lugar corresponde a los servicios personales, en el cual el servicio doméstico constituye el segmento de mayor peso. De hecho, en este sector tan heterogéneo ha habido modernización técnica, pero esta ha tendido a concentrarse en la informática y en los sectores financieros.

Sin embargo, como los servicios modernos están causando cambios en las características de los denominados estratos medios, conviene detenerse en este hecho. Según Prieto (1986), la transnacionalización de los servicios ha sido la continuación lógica de la transnacionalización de bienes. Ha tenido lugar en grandes conglomerados bancarios y de seguros, de publicidad, de auditoría y de muchos otros servicios que prestan apoyo esencial a la internacionalización de la economía de los países centrales. Trátese o no de empresas transnacionales, la modernización se ha dado en los transportes, a través de la tecnología de contenedores y la integración de diferentes modos de transporte en operaciones a gran escala. Y en la propia producción de bienes misma ha crecido el componente de servicios, en especial informáticos, lo que es particularmente válido en el caso de los bienes de alta tecnología y gran dinamismo en el comercio internacional. La tecnología influye en la internacionalización y la marcada transformación de ciertos servicios -incluso algunos de índole profesional para los cuales antes era casi obligatorio recurrir a capacidades nacionales (por ejemplo, servicios de arquitectura y consultorías de gestión)-, en los que se aplican técnicas computarizadas de diseño o de gestión. Cabe señalar que estos procesos de modernización pueden conducir a formas mayores de concentración.

Pero además de la modernización de los servicios por la incorporación de nuevas tecnologras, se están dando cambios en las formas tradicionales de organización de algunos de ellos, lo que repercute en la estructura del poder económico y social. En este sentido tiene particular relevancia la fusión de las instituciones bancarias con las no bancarias del área financiera, dando origen así a "bancos múltiples" que pasan a administrar libretas de ahorro, y realizan operaciones de mercado abierto, suscripción de fondos de inversion y fondos de capital, operaciones de financiamiento del sistema de vivienda, operaciones individuales o industriales de la construcción y otras. Por lo demás, los bancos de inversión a menudo se han constituido en bancos comerciales, y la banca se ha expandido a otros sectores, formándose de este modo grandes grupos económicos con intereses diversificados. En este proceso han desempeñado un papel decisivo los grupos extranjeros.

Como se ha visto, la heterogeneidad del sector de los servicios es grande y los estratos sociales que lo componen son muy diversos. Se suele establecer una conexión entre el sector terciario y los estratos medios. Aunque esta no sea enteramente apropiada por el hecho de que esos estratos también tienen presencia significativa en otros sectores de la economía, no se puede desconocer que en América Latina su crecimiento y significación social y política ha estado ligada a las características del sector terciario.

Según Wolfe (1990), debido a la crisis de los años ochenta - aunque quizás también a otros factores anteriores no sólo económicos- los estratos medios asalariados vivieron situaciones de inseguridad y experimentaron bajas en sus ingresos. Esto habría hecho crecer la disparidad entre la realidad y las aspiraciones de tales grupos —en especial las de consumo moderno y de movilidad ascendente entre generaciones-, aspiraciones que se habrían arraigado en los años de expansión económica. En los estratos medios, los grupos que habían mostrado un mayor crecimiento correspondían a la tecnocracia, a los profesionales y a la burocracia del sector público, principales fuentes de ocupación de los egresados universitarios. Pese a la crisis y a las políticas de desburocratización, la dotación en términos de número de personas se mantuvo y en algunos casos se incrementó, pero a costa de reducciones de ingresos y pérdida de calidad de sus condiciones de trabajo. 
Rama y Faletto (1986) ponen de relieve que los marcos de referencia intelectuales de esos grupos cambiaron marcadamente, aproximándose a los de sus pares del mundo desarrollado, con orientaciones vinculadas a la eficiencia, la especialización funcional, la organización racional y nuevas concepciones del Estado. Los estratos medios dependientes o asalariados surgieron algunos con el incremento de las funciones administrativas del Estado, y otros con el desarrollo de los servicios comerciales para un consumo urbano creciente, o bien con la expansión de los servicios sociales y comunitarios, en particular los de educación y salud. En cambio, los estratos medios independientes no manuales perdieron peso en toda la región, se vieron acosados por el crecimiento del Estado y por las grandes organizaciones económicas $\mathrm{e}$ incluso en muchos casos perdieron status frente a otros grupos, como por ejemplo el de los obreros calificados. Por otra parte, la tecnocracia y la burocracia $\rightarrow$ o más bien los miembros de ellas- desempeñaron un papel clave, puesto que administraron de manera ad hoc las funciones de los recursos públicos tanto en la acumulación de capital como en la reproducción de la fuerza de trabajo y pasaron a articular y mediatizar las relaciones entre las clases o entre los intereses particulares y esos recursos. La función de mediatización las transformó en los sujetos virtuales de la política.

\section{La informalidad}

Son muchos los autores que han insistido en que subsisten rasgos concentradores y excluyentes en el actual estilo de desarrollo, cuya manifestación más visible es la magnitud de la fuerza de trabajo "informal". El Programa Regional del Empleo para América Latina y el Caribe (PREALC, 1988a) señala que entre 1980 y 1983 el crecimiento de la población económicamente activa no se desaceleró con la crisis. En una primera etapa, el ajuste descansó principalmente en un rápido aumento del desempleo abierto y luego en la fuerte expansión de la ocupación informal urbana. El bienio 1984-1985 se caracterizó por el inicio de una recuperación parcial: el total de desocupados descendi6 $8 \%$ pero en gran medida lo hizo por el aumento del empleo informal. El empleo formal urbano crecí anualmente alrededor de $2.6 \%$, en tanto que el informal to hizo a razón de casi $7 \%$. En 1985 y 1987 la recuperación se acentuó, pero la fuerte expansión del empleo informal se mantuvo, y de hecho en ella se basó el ajuste del mercado laboral. Cabe tener en cuenta que hay empleo informal en todos los sectores económicos: por ejemplo, en la industria es relativamente alto y cercano al promedio de los otros sectores. De aquí que no sólo sea importante definir quiénes conforman la fuerza de trabajo informal en términos individuales, sino también tener presente que muchos se vinculan a "empresas informales".

Citando a Víctor Tockman, los autores Castillo y Cortellese (1988) describen la "empresa informal" como una organización rudimentaria, sin una clara división del trabajo ni de la propiedad de los medios de producción, con muy poco capital comprometido y bajos requisitos de habilidades. La "empresa informal" tiene dificultades de acceso a los mercados competitivos y a la base de los mercados concentrados, y su posibilidad de competir está determinada por el ingreso medio como variable de ajuste. Dada la restricción del mercado, mientras mayor sea el excedente de mano de obra, menor será el ingreso percibido por cada persona que trabaja en actividades informales. En los momentos de crisis, anota Wolfe (1990), el descenso de la producción de las industrias modernas de bienes de consumo, de la capacidad de importación y del poder de compra de los consumidores ofrecían un radio de maniobra a las industrias pequeñas no reglamentadas, pero es probable que haya sido aprovechado por las grandes empresas a través de la utilización del sector informal para la producción a destajo y la comercialización del producto en el comercio callejero.

Según el PREALC (1987), si bien la informalidad deriva en gran medida de la búsqueda de ingreso para sobrevivir, los gobiernos se han adecuado pasivamente a tal situación por la vía de la tolerancia y la legitimización progresiva de situaciones de hecho. Tal es el caso de las construcciones precarias, del funcionamiento de servicios de transporte sin reglamentación y del crecimiento de la actividad comercial no autorizada. Incluso como respuesta a la crisis, en muchos casos se buscó dar mayor flexibilidad al mercado de trabajo, reformando las disposiciones al respecto, o disminuyendo la fiscalización y aumentando la tolerancia ante la evasión de las disposiciones vigentes. Como es de suponer, todos estos hechos afectan además la capacidad de los sindicatos de los sectores organizados para llevar a cabo una política activa de negociación colectiva. Es importante destacar, por último, lo que diversos autores han sostenido, esto es, que las relaciones entre las actividades modernas y las informales reflejan una especie de balance comercial. El segmento informal adquiere en el moderno 
sus bienes de capital, muchos de sus insumos de producción y la mayor parte de los bienes que consumen sus familias, y a su vez vende a los asalariados del segmento moderno una variedad de bienes y servi- cios que mantienen aproximadamente equilibrado ese balance comercial. De este modo, la situación dual en términos de incluidos y excluidos no significa la ausencia de relaciones entre ambos grupos.

\section{II}

\section{La estratificación social y la generalización de intereses}

Frente a la heterogeneidad anteriormente descrita, el problema social y político que se plantea es el de la posibilidad de acción colectiva, es decir, de que ciertos sectores o grupos puedan determinar el proceso social y político o al menos influir en él. Al respecto es preciso examinar ciertas condiciones de la acción colectiva que están dadas por la capacidad de generalizar y organizar intereses comunes, ya sea para la defensa corporativa o para la proyección de esos intereses como propuesta de orden social.

\section{La heterogeneidad y la posibllidad de generalizar intereses a nivel empresarlal}

En América Latina el predominio casi sin alternativa del pensamiento neoliberal podría llevar a la fácil conclusión de que el empresariado ha conseguido no sólo generalizar sus intereses como sector, sino que ha logrado convertirlos en un proyecto capaz de imponerse como común a la sociedad en su conjunto. El término gramsciano de hegemonía sería aplicable entonces al empresariado como clase dirigente. Sin embargo, en ese nivel de abstracción no estamos en condiciones de comprender las acciones desplegadas por el empresariado, que harían posible, con determinadas características, que se ejerza esa hegemonía.

Al respecto, se aprecia que el empresariado ha aumentado su heterogeneidad más allá de lo que tradicionalmente permitió diferenciarlo en relación con su tamaño y el sector de la economía en que actuaba. Esta situación dificulta sus posibilidades de generalizar sus intereses. Las diferencias de nivel tecnologico de las empresas tienen importancia pero aún más la tienen la índole y el nivel de su articulación con otras empresas, especialmente en el ámbito transnacional.
La información sobre los altos sectores empresariales es muy escasa, ya que se guarda reserva sobre sus reales vinculaciones; el grado de control sobre diversas empresas y la conformación de grupos económicos. Sin embargo, los estudios existentes tienden a resaltar el papel cada vez mayor de las grandes empresas transnacionales en la conformación de los principales grupos económicos, así como el predominio del segmento financiero sobre los demás.

Salvo en ciertos aspectos muy genéricos, como el de las políticas impositivas, no suele ser fácil generalizar intereses a nivel global. Por el contrario, se suscitan conflictos entre diversos actores que presionan al Estado para obtener medidas que los favorezcan. Los actores principales de esos conflictos suelen ser, por una parte, los grupos económicos nacionales ligados a las empresas transnacionales $\mathrm{y}$, por otra, las empresas orientadas al mercado interno.

Los grupos económicos transnacionales tienden a la autorregulación, razón por la cual son fuertes impulsores de la idea de la prescindencia estatal en la economía y del máximo grado de apertura al exterior. A su vez, las empresas que producen para el mercado interno tienden a desarrollar formas de organización corporativa para la defensa de sus intereses, casi siempre ligados a una producción específica, y tienden a demandar regulación estatal, especialmente en términos, entre otros, de protección arancelaria, precios garantizados, créditos blandos y asistencia técnica.

Estos actores centrales por el lado empresarial no son nuevos en América Latina sino que, por el contrario, han marcado casi siempre la tónica de los sectores dominantes, alternándose muchas veces en el predominio. Lo que se advierte ahora es que las ventajas que adquirieron las empresas ligadas a la producción para el mercado interno durante la etapa 
de suistitución de importaciones se han ido perdiendo en gran medida y que vuelve a tener mayor peso el sector de exportacion. No obstante, la actual presencia de grupos económicos transnacionales suele trascender la nítida diferenciación de mercados internos y externos. La trasnacionalización segmentada del mercado interno de bienes y servicios, así como la creciente trasnacionalización del mercado laboral, genera inclusive serias dificultades para poder establecer las anteriores diferenciaciones.

El gran empresariado moderno suele ser bastante cosmopolita, ligado a la economía internacional y vinculado a sectores muy diversos de la producción en el país y en el extranjero. Su participación en grupos económicos de integración vertical y horizontal y en rubros muy diversos de la economía, le dan una gran capacidad de autorregulación y disminuyen o eliminan la necesidad de representar sus intereses ante el poder público. Por lo demás, de ser necesario, se hace escuchar directamente por las autoridades, cautelosas ante las consecuencias de una posible movilización de su enorme poder económico. Esta situación, por lo demás, quedó bastante clara frente a la crisis de la deuda externa.

Fuera de estos sectores, la generalización de los intereses del sector empresarial, siempre difícil debido a las necesidades diferentes y hasta contrapuestas de sus diversas actividades, suele hacerse a través de organizaciones gremiales de antigua data en la región. Estas en general actúan como grupo de presión, cuya eficacia suele ser mayor mientras más específico sea el sector representado. Pero actualmente pareciera tenderse a una progresiva pérdida de poder de las asociaciones gremiales de empresarios. Esta situacion guarda coherencia con la mayor heterogeneidad empresarial a que hacíamos referencia y se ve reforzada por el hecho de que las grandes empresas transnacionales tienden a integrar subordinadamente a otros núcleos empresariales, vinculando los intereses de éstos a los propios, alterando así los lazos de solidaridad que se podrían producir entre empresarios de similar condición.

Pese a todo, cabe recordar que en varios países de la región la percepción de una amenaza grave (real o supuesta, pero sentida como real) contra los fundamentos de la existencia de la clase empresarial provocó en ella una fuerte reacción en cuanto tal y robusteció sus organizaciones gremiales. Posteriormente, la oleada de regímenes autoritarios en el Cono Sur y en otros países de la región se impuso y se mantuvo con el fuerte respaldo de esas organizaciones gremiales, las que acrecentaron aún más su fuerza y capacidad de intervención. Esto ha hecho que aun en el período de consolidación democrática hayan seguido siendo bastante fuertes. Pero su fuerza es más política que económica y tiende a disminuir a medida que el proceso de modernización va contribuyendo a la conformación predominante de grandes grupos económicos nacionales ligados al capital transnacional.

\section{La generallzación de intereses de los estratos medios}

Aparte la dificultad teórica y empírica de definir a los estratos medios, las transformaciones ocurridas en materia de representación, organización y acción de ciertos grupos con los cuales se les identificaba son apreciables.

En efecto, en el pasado los estratos medios cobraban visibilidad a través de un numeroso contingente de empleados de servicios tanto públicos como privados de capacitación y de reproducción de las condiciones de vida; una capa de profesionales y técnicos, y una extensa pequeña burguesía ligada a las diversas actividades de la economía y especialmente numerosa en el comercio y el transporte. Su vinculación directa con el Estado, o su dependencia de la demanda de los estratos populares o medios facilitaba su articulación en proyectos desarrollistas encaminados a la incorporación social de los sectores marginales al sistema.

La posibilidad de generalizar intereses era fuerte en el sector público, con capacidad de presión a nivel tanto sindical como político. A nivel profesional y técnico, las asociaciones gremiales lograban bastante exito en la defensa corporativa. La pequeña burguesía, en cambio, tenía grandes dificultades para lograr una generalización de intereses, salvo en casos esporádicos en que lograba movilizarse a través de organizaciones que, sin tener mayor cohesion, podían transformarse en referentes de acción colectiva en situaciones muy específicas.

Hoy el panorama se encuentra bastante cambiado, aunque en grados que varían mucho según las situaciones nacionales (CEPAL, 1991).

Así, ha habido una fuerte disminución del empleo público, producto de la acelerada privatización del sector estatal productivo y de servicio: En los casos en que no ha habido una directa reducción del empleo estatal, su importancia relativa ha disminuido en actividades de especial importancia, como las de educación y salud, las que han entrado en una des- 
medrada competencia con empresas privadas que desalientan las acciones reivindicativas de sus trabajadores.

La crisis del sector público, experimentada de muy diversas maneras en los países latinoamericanos, significó la pérdida de posiciones estructurales que permitían una relativa capacidad de generalizar intereses y conformar organizaciones fuertes. La emergente empresa privada en los servicios sociales no sólo ha diversificado el contradictor de referencia, sino que ha contribuido también a acrecentar la heterogeneidad. Este aumento de la heterogeneidad hace más difícil la generalización de intereses, ya que no sólo ha traído consigo abismantes diferencias de remuneraciones, sino también diferentes modalidades de vinculación con la empresa y de trabajo.

Por su parte, los profesionales y técnicos ven acelerarse la pérdida del carácter "liberal" de sus actividades y pasan a incorporarse, en muy diversas condiciones, a empresas en las cuales suele ser muy importante la inversión en equipos y tecnología. El caso de la salud es especialmente ilustrativo al respecto, pero en todos los rubros ocurren situaciones similares. A lo anterior hay que agregar la emergencia de nuevos técnicos y profesionales que se incorporan a empresas muy directamente vinculadas a la producción, como la moderna publicidad, las comunicaciones y la informática. Su falta de tradición gremial y su fuerte dependencia de la inversión tecnológica los dejan bastante poco capacitados para la generalización de intereses a cualquier nivel. $Y$ por tratarse de actividades recientes, la expectativa de movilidad social individual es muy elevada, lo que desalienta toda orientación por la acción colectiva.

Por último, la pequefía burguesía, que tiene siempre dificultades para generalizar sus intereses, ve acrecentarse también su heterogeneidad. Esto sucede no sólo como consecuencia del avance tecnológico y de la inserción en el modelo económico dominado por la tendencia a la transnacionalización, sino también por la emergencia de un nuevo segmento de pequeños empresarios, surgidos del desplazamiento del empleo público, que emprenden actividades por cuenta propia en el comercio, el transporte e incluso la industria y la agricultura. Tiende a extenderse asimismo la dependencia del empresariado mediano y pequeño respecto de la gran empresa: en los servicios a través de la subcontratación de tareas y en el sector productivo a través de redes de elaboración, distribución y comercialización de la producción (agrícola y pesquera) o de la integración de partes (industria). El aumento de la heterogeneidad y la dependencia refuerza por cierto la dificultad de generalizar intereses y se desemboca en una disminución de la presencia de los empresarios pequeños y medianos en las organizaciones gremiales del empresariado.

Ahora bien, si además de considerar los cambios ocurridos en cada segmento de los estratos medios, atendemos a la alteración de la proporcionalidad entre eilos, se aprecia que aumenta la presencia de los segmentos más permeables a la autoidentificación empresarial y a una ideología consecuente con ella, lo cual refuerza el individualismo y contribuye a atomizar dichos estratos. A la vez, a éstos se les hace más difícil configurar posiciones de acercamiento a los estratos populares, como hicieron en períodos anteriores de mayor integración social. $Y$ por último, la segmentación de los mercados de bienes y servicios y su internacionalización alejan a los estratos medios de la defensa de políticas redistributivas y de integración de los estratos populares.

\section{La generalización de Intereses del sector obrero}

A lo largo de los años la región ha prestado atención preferente al sector obrero, por la importancia atribuida y real que, a partir de la industrialización latinoamericana, ha tenido en la conformación de fuerzas sociales y políticas de gran gravitación. El patrón de desarrollo europeo, que de manera implícita o explícita está siempre presente en los análisis del tema en la región, guió muchos de los estudios realizados en términos comparativos (entre otros, el de Przeworski, 1983).

La capacidad de generalización de intereses en el sector obrero se daba casi por descontada, a la vez que las tesis socialistas le conferían claramente la posibilidad revolucionaria de trascender tal generalización y proyectarse como el fundamento de una reorganización social. Lo que para otros parecía difícil, para los obreros se presentaría como algo natural. Aunque se cuestionara su supuesta misión histórica, la organización sindical era un hecho a medida que avanzaba la industrialización, y su papel político también parecía claro en fenómenos como el populismo o la configuración de lo que se ha denominado el "Estado de compromiso".

Los estudios de la CEPAL sobre este sector dan cuenta de cambios de importancia que inciden muy directamente en su capacidad de generalizar intereses y de actuar como sujeto colectivo (CEPAL, 
1989). Según una estimación cuantitativa bastante ligada al problema de la "asalarización" y "des-asalarización" de la mano de obra, la primera, mirada como un fenómeno natural del desarrollo capitalista, no sería lineal, ni constante e irreversible: en general, habría habido un proceso de asalarización, aunque no muy vigoroso, en el período 1950-1980, pero con la crisis de los años ochenta se habría producido el proceso inverso.

En la actividad agrícola, siempre según esos estudios, se habría dado una asalarización acelerada, producto de la mayor capitalización en el campo que trajo consigo el desarrollo de la moderna empresa agrícola orientada a la exportación y al consumo interno. Pero contrariamente a lo que cabía esperar, esa mayor asalarización no se ha traducido en una mayor homogeneidad de los obreros agrícolas, lo cual obviamente dificulta la generalización de intereses. Por otra parte, la asalarización agrícola no sólo está vinculada con las condiciones propias del tipo de empresa, sino que también con las características estacionales de la producción. Estas últimas han dado origen a un importante segmento de trabajadores temporeros de rasgos muy peculiares, entre los cuales hay mucha mano de obra urbana y gran presencia de mujeres. Una situación similar, con diferencias propias de la actividad, se aprecia en el sector pesquero.

En el sector industrial, los estudios citados muestran que es muy distinta la situación del obrero en la gran industria moderna de bienes de capital o intermedios, en la de bienes de consumo durables o no durables, en la mediana y pequeña industria, en talleres o en la construcción. Si a esto se suman las diferencias de capacidad tecnologica, queda de manifiesto una gran heterogeneidad que se manifiesta en intereses diversos e incluso contrapuestos.

En la minería se observan también cambios de gran importancia que han afectado la capacidad de acción de sectores que tradicionalmente han tenido gran presencia sindical y política. A través de un largo proceso, acelerado en los últimos años, la tecnificación de las faenas ha ido desplazando la producción basada en el uso intensivo de mano de obra, que agrupaba a grandes masas de trabajadores de escasa calificación en condiciones de "campamento", con intensa vida comunitaria. El número de trabajadores mineros se ha reducido fuertemente, a la vez que se han elevado los niveles de calificación requeridos. Aunque subsisten algunas empresas mineras tradicionales, ellas están en franca declinación y sus expectativas de sobrevivir sólo descansan en una reconversión que significaría la expulsión masiva de mano de obra, la que se aceleraría a medida que se proceda a privatizar la actividad. En países de tradición minera como Bolivia, Chile y Perú, la situación ha ocasionado movilizaciones defensivas de los trabajadores afectados, las que no han logrado detener el proceso de expulsión, aunque en algunos casos han retrasado la privatización. En términos gráficos se podría decir que la imagen del minero del carbón o del cobre tiende a ser desplazada por la del trabajador petrolero. Su menor número, alta calificación y buenos ingresos generan otro tipo de intereses, distintos de los de la gran masa obrera del país.

Por último, los estudios citados señalan que se ha producido un fuerte incremento de los obreros que trabajan en el sector de los servicios, dando lugar a lo que se ha denominado la "terciarización de la clase obrera". Esto es coherente con la tendencia mundial a la tecnificación de la producción industrial y al crecimiento del sector terciario. El incremento de estos obreros se ha dado de preferencia en los transportes, las comunicaciones, las reparaciones y los servicios personales no domésticos (CEPAL, 1989). Con ello se ha generado una clase obrera terciarizada, que representa un tercio o más de la población económicamente activa en muchos países de la región y cuyas características son distintas de las que presenta la clase obrera industrial que sirvió de base para todos los análisis sobre condiciones y acción en términos de conflicto de clases. Las diferencias se dan no sólo porque los obreros terciarizados no tienen participación directa en la producción material, sino también porque las condiciones de su trabajo no facilitan la identidad y la acción colectivas. Generalmente trabajan aislados o en pequeñas empresas, su estabilidad laboral y su situación contractual suelen ser precarias y las empresas del rubro, incluso las grandes, tienden a subcontratar actividades con pequefos y medianos empresarios, aumentando así la precariedad laboral. Si se considera la situación de cada uno de los segmentos del sector obrero, se advierte que incluso a ese nivel es difícil generalizar intereses. La heterogeneidad no sólo hace disminuir la cantidad de trabajadores que están en una situación equivalente, sino que deteriora en cada caso las condiciones en que podría tener lugar esa generalización.

Por otra parte, si se toma en cuenta la totalidad de los trabajadores manuales, se advierte que han perdido fuerza aquellos segmentos que solían asumir el liderazgo de las demandas obreras. Al respecto, la disminución de la clase obrera industrial aparece como 
el dato más significativo, al cual habría que agregar la anterior disminución del combativo contingente minero.

La rearticulación del sector obrero no parece fácil, en vista de su pérdida de identidad como "clase obrera" a raíz de los desplazamientos que han otorgado creciente peso al sector terciario en desmedro del productivo. A la vez, la mayor heterogeneidad de las empresas redunda en fuertes diferencias entre los obreros que dificultan la generalización de intereses. Más aún, cuando se logra cierta generalización, ello suele ocurrir respecto de empresas y actividades específicas, lo que inclina más al aislamiento y la defensa corporativa que a la búsqueda de coincidencias más amplias.

Como fenomeno adicional, tienden a expandirse en el sector las relaciones laborales precarias. En algunos casos las diferencias entre asalarización y desasalarización pierden sentido pues surgen nuevas formas de vinculación trabajador-empresa y de organización de tareas, nuevos sistemas de remuneración y otras condiciones que configuran situaciones que se apartan de las clasificaciones tradicionales. No se trata de los modos precarios de la relación laboral que existen desde antigua data en el trabajo doméstico o en las faenas temporeras agrícolas, sino de nuevas formas de relación laboral, distintas del contrato formal de trabajo estable y remunerado periódicamente. Ahora el contrato tiende a ser por tarea, sin garantía de estabilidad ni de reproducción social, y en él la empresa se desliga del trabajador en todos los aspectos, salvo en la compra del trabajo incorporado al producto en cuestion. Esto genera escasa solidaridad laboral: el trabajo se hace competitivo entre los trabajadores, los cuales muchas veces ni siquiera operan en un mismo espacio; a la vez, la jornada de trabajo no tiene límites, pues no se compra tiempo, sino tarea, y de existir limitaciones legales la prolongación de éstas se supera mediante tiempo extraordinario o, más fácilmente, a través de la contratación de otras jornadas en otras empresas.

En suma, las transformaciones que hemos reseñado - las derivadas de la asalarización agrícola, la disminución y cambio de condición de los mineros, la reducción de la clase obrera industrial, la terciarización obrera, la "precarización" laboral y la creciente heterogeneidad de los trabajadores manuales- disminuyen las posibilidades de generalizar los intereses de los distintos segmentos del sector obrero. A la vez, pierde fuerza la reivindicación laboral - generalmente planteada respecto del Estado— de medidas de reproducción de la fuerza de trabajo a través de políticas de salud, educación, vivienda y previsión. La crisis del naciente Estado benefactor latinoamericano y la privatización de esos servicios desdibuja la posibilidad de generalizar intereses a ese nivel.

\section{La marginalidad}

Desde la perspectiva de las posibilidades de generalización de intereses y de organización y acción colectiva, parecería conveniente usar el concepto de marginalidad, más que los de pobreza o informalidad, to cual no desmerece el uso de tales términos para otros propósitos.

En efecto, las posibilidades de generalización y representación de intereses de los distintos segmentos de la población no se definen por sus diferentes niveles de ingreso, sino por sus diferentes posiciones estructurales. El hecho de que una determinada posición estructural signifique una situación de pobreza no implica que ambos conceptos sean equivalentes. Por el contrario, hay muchos pobres dentro del sector obrero, pero esa condición no les hace perder su calidad de obreros.

Con respecto a la informalidad, la distinción resulta quizás más difícil, puesto que los trabajadores marginales normalmente establecen relaciones laborales informales. Pero el término formalidad tiene su formulación más concreta en su referencia al encuadramiento en las formas jurídicas vigentes para la relación laboral, con lo cual no es aplicable a un vasto segmento de trabajadores marginales que, por actuar como productores directos de bienes y servicios o por otras condiciones, no entran en relaciones laborales que puedan formalizarse. Lo mismo cabe decir respecto de la formalidad jurídica de sus actividades independientes.

Las dificultades con que se tropieza al tratar de definir la informalidad en términos no jurídicos tampoco hace aconsejable tal opción, aunque, como hemos visto, ella es de gran utilidad en el momento de determinar las condiciones económicas estructurales de la estratificación. Las consideraciones de Tokman (1979) siguen siendo válidas al respecto, aunque la generalización de intereses diff́cilmente pueda verse en términos de informalidad.

El concepto de marginalidad, a pesar de su oscuridad teórica, tiene una connotación de exclusión que resulta de particular importancia ante la fuerte gravitación de un modelo económico que implica creciente integración sistémica a la vez que exclusión social. 
Esto último es la marginación social, que excluye estructuralmente tanto de las relaciones de producción prevalecientes como de la participación en el producto social.

Naturalmente, la marginalidad es un concepto relativo, puesto que ciertas situaciones del sector obrero e incluso del segmento de trabajadores no manuales de baja calificación significan grados importantes de marginalidad. Pero aquí el concepto alude fundamentalmente al tipo de vinculación con la actividad productiva que tienen los sectores que se han denominado marginales, considerándose como tales a los que no tienen una relación regular de venta de fuerza de trabajo ni constituyen una pequeña burguesía vendedora de una producción autónoma de bienes y servicios.

Conviene tener en cuenta que, según se ha probado en estudios empíricos, la informalidad no es siempre e inevitablemente sinónimo de subempleo, baja productividad o extrema pobreza (CEPAL, 1989). Esto ha conducido a que actualmente se intente, a través de definiciones cuantitativas de niveles de vida, una conceptualización del fenómeno de la pobreza, el que ha sido objeto de varios análisis recientes cuyos resultados son inquietantes.

La conceptualización de la informalidad o de la pobreza no busca por cierto determinar si existen o no condiciones propicias para la generalización de intereses, la organización o la acción colectiva. Por el contrario, busca identificar situaciones que permitan medir niveles y modalidades de desarrollo económico, por lo general con miras a la formulación de políticas para enfrentar situaciones definidas como problemáticas. Esto queda especialmente claro respecto de las mediciones de pobreza y la propuesta de cursos de acción gubernamentales para atender las situaciones de mayor deterioro.

En cambio, la preocupación por la marginalidad ha tenido desde su inicio una connotación bastante política. En los años cincuenta preocupaba la posibilidad de que los sectores marginales se movilizaran en forma espontánea o inducida. Posteriormente, en los agitados años setenta, lo que se analizaba era su potencialidad revolucionaria.

Sin embargo, el concepto de marginalidad tuvo en sus orígenes un componente espacial, por cuanto se identificó como marginales a quienes vivían en asentamientos precarios ubicados al "margen" de las ciudades, en "poblaciones callampas", "favelas", "barriadas", "pueblos jóvenes", u otros. Ślo más tarde se miró la marginalidad como una posición estructural ligada preferentemente a la inserción ocupacional; pero a la vez se asimiló implícitamente la marginalidad ocupacional a la espacial, aunque estudios empíricos realizados en los años sesenta muestran que la composición de las poblaciones populares es mucho más variada y que no necesariamente concentra la marginalidad estructural. ${ }^{1}$ De hecho, los estudios siguen haciéndose en "poblaciones", sin que la marginalidad estructural haya sido objeto de mayor análisis.

Las complejidades señaladas impiden ofrecer un cuadro claro de la evolución de la marginalidad estructural, por la carencia de información precisa para ese efecto. En todo caso, si se considera las categorías aproximables de pobreza e informalidad, es posible deducir que la marginalidad estructural abarca un segmento importante de la población que no parece haber disminuido en los años setenta y ochenta.

Sin ánimo de ser exhaustivo, se puede señalar que caen en esa categoría el comercio ambulante, un porcentaje importante del servicio doméstico, los campesinos en la economía de subsistencia, los trabajadores autónomos en los servicios personales, los desocupados crónicos y lumpen en general.

Nuevamente nos encontramos aquí con una gran heterogeneidad de posiciones, pero en este caso la heterogeneidad es tanta que, salvo a niveles muy abstractos, la generalización de intereses se torna prácticamente imposible.

Por lo general se atribuye a los sectores marginales demandas de bienes de urbanización, así como movilizaciones para apoyarlas, en las que tienen particular relieve las necesidades de vivienda. Sin embargo, las organizaciones y acciones colectivas que surgen para estos efectos responden más bien a la marginalidad espacial localizada en las poblaciones populares, las que por razones de crecimiento vegetativo o inmigratorio alcanzan densidades que se tornan insoportables. Por lo tanto, es difícil afirmar sin más que el interés por los bienes de urbanización es generalizable a nivel de marginalidad estructural, aún cuando es posible que quienes están en tal situación sean la mayoría de las personas que se movilizan en ese sentido.

Las demandas de bienes de urbanización, que han tenido cierta importancia en América Latina, no parecen guardar relación directa con posiciones en la estructura productiva, salvo que, naturalmente, la necesidad de tales bienes al nivel más básico correspon-

' Entre otros, uno que se llevó a cabo en Chile (CIDU, 1972). 
de a los sectores más desposeídos. Lo que sí se percibe es que en situaciones de marginalidad esas demandas tienen como único destinatario el Estado, a diferencia de lo que ocurre con obreros o empleados, que pueden recurrir a la parte empresarial para que incorpore este particular costo de la reproducción de la fuerza de trabajo.

Se observa aquí un rasgo importante y bastante genérico de los grupos marginales: tengan ellos o no intereses generalizables, lo que sí tienen es un proveedor generalizado, que no es otro que el Estado. Ante él plantean sus demandas que adquieren homogeneidad frente a necesidades básicas ligadas a la subsistencia, y no en el desarrollo autónomo de posiciones estructurales.

De aquí surge la noción de plebe urbana (aunque en América Latina no es sólo urbana) con la que se puede denotar esta marginalidad. La plebe urbana no tiene intereses generalizables como sector, ni puede, por consiguiente, organizarse. Por el contrario, permanece como conjunto de sujetos aislados, sin conexión social de unos con otros, por más que permanezcan en una situación similar. La condición de masa impide la constitución de un sujeto colectivo y cada uno trata de establecer una relación directa, o intermediada por el clientelismo, con el poder. Este es el que le puede dar una participación en el producto social que le permita satisfacer las necesidades vitales que su actividad no le hace posible cubrir.

Dada la posicion estructural de la plebe urbana, que dificulta toda generalización de sus intereses en cuanto tal y toda organización social, su acción tiende a tener implicaciones políticas, aunque en principio esa actividad no le interese. S6́lo los liderazgos políticos carismáticos o las movilizaciones sociales disruptivas son capaces de involucrarla con fórmulas de integración comunitaria y promesas de una mejor disposición de las autoridades hacia sus necesidades.

La relación de este sector con fenómenos como el populismo y el autoritarismo merecería ser objeto de análisis profundos, como lo demuestran algunos estudios pioneros (Medina Echavarría 1964; Germani, 1960; Weffort, 1970).

\section{La organizaclón social y sus dificultades}

Como se ha venido señalando, la creciente heterogeneidad estructural se manifiesta directamente en problemas de generalización de intereses que dificultan la organización social a partir de ellos. Naturalmente esto no hace que las organizaciones desaparezcan, pero sí provoca cambios en ellas que afectan su capacidad de acción. Además, surgen sectores que quedan fuera de las organizaciones.

Ahora bien, las principales organizaciones de intereses siguen siendo las que agrupan a empresarios, por una parte, y a trabajadores, por la otra. $Y$ en ambas ha habido modificaciones de importancia.

Entre los empresarios han perdido fuerza aquellas organizaciones empresariales ligadas al desarrollo industrial de la etapa de "crecimiento hacia adentro", en la cual sus esfuerzos se orientaron fundamentalmente a lograr que el Estado aplicara políticas proteccionistas: entre otras, la Confederación General Económica en Argentina, la Sociedad de Fomento Fabril en Chile y la Cámara de Industrias en Uruguay. A la vez, el predominio de los grupos económicos vinculados a las empresas transnacionales, que recurren a la autorregulación o presionan directamente al gobierno, resta poder a las organizaciones empresariales.

No obstante lo anterior, algunos estudios (PREALC, 1988b) indican que la pérdida de peso económico de los gremios empresariales suele verse compensada coyunturalmente por su gravitación política. Así ocurrí cuando regímenes autoritarios acudieron en defensa de la empresa privada en los agitados años setenta, y ocurre nuevamente cuando la búsqueda de equilibrios macroeconómicos lleva a formas de concertación social en la que los gremios empresariales son convocados como representantes del capital frente a la fuerza de trabajo organizada sindicalmente.

Con independencia de estas situaciones coyunturales, los gremios empresariales conservan cierta fuerza cuando están vinculados a actividades especializadas de la producción. Pero en tal caso su acción tiende a ser más bien de carácter defensivo frente al deterioro que les significa una política económica que reconoce la hegemonía del segmento transnacionalizado.

Por el lado de los trabajadores los cambios parecen más visibles y más drásticos (Wolfe, 1990). Las modificaciones en la composición de la fuerza laboral han debilitado grandemente las organizaciones sindicales. En esto han incidido particularmente la disminución de la clase obrera industrial, la caída del empleo público, la terciarización obrera, los cambios en la organización del trabajo, la precarización, la remuneración por producto en reemplazo de la remuneración por tiempo $y$, sobre todo, una heterogeneidad cada vez mayor de la fuerza laboral que dificulta la generalización de intereses.

En general, las organizaciones sindicales que han 
perdido más fuerza son las de segundo y tercer nivel. Cada vez es más difícil -y a veces incluso está proscrita legalmente - la negociación de las condiciones de trabajo por rama de actividad o a nivel nacional. Sólo en las grandes empresas se suele mantener y robustecer la actividad sindical, tecnificando bastante el estilo de la negociación colectiva y tratando de resistir la tendencia al contrato individual.

En los momentos de crisis de los años ochenta, las organizaciones sindicales nacionales lograron liderar algunas movilizaciones defensivas frente a las políticas de ajuste recesivo. Sin embargo, aún cuando lograron algunos éxitos, la persistencia y agudización de la crisis las hicieron perder fuerza hegemónica y, en general, las dejo sin capacidad de resistencia frente a políticas que afectaban directamente aspectos básicos de su razón de ser, como la baja de salarios y los despidos masivos.

Posteriormente, frente a las necesidades de concertación social para garantizar la eficacia de las medidas de equilibrio macroeconómico hubo una revaloración política de las organizaciones sindicales nacionales. Pero su representatividad sufrí un pronto deterioro porque su función era la de limitar demandas salariales: los beneficios inmediatos y directos de tal sacrificio no estaban claros para los sectores supuestamente representados.

Por otra parte, a excepción de esas situaciones específicas, la fuerza de la organización de trabajadores a nivel nacional ha ido desmejorando a medida que la relación entre trabajadores sindicalizados y no sindicalizados es cada vez más favorable a los segundos, especialmente con la incorporación a la fuerza de trabajo de mujeres con poca tradición sindical y de trabajadores por cuenta propia e informales.

Podría decirse entonces que hoy se tiende a la organización sindical a nivel de empresa, siendo parcial y de diverso peso según el segmento de trabajadores de que se trate. El tipo de empresa y la índole de la relación laboral son factores determinantes de la posibilidad de los trabajadores de organizarse y de la fuerza que puedan desplegar en defensa de sus intereses.

En los estratos medios la organización sindical se ha debilitado tanto por la reducción del sector público como por el aumento de la proporción de trabajadores por cuenta propia en ellos.

En la marginalidad, por último, y dadas sus características, la organización es muy débil o casi inexistente. A nivel de marginalidad espacial, las organizaciones que se forman suelen tener un carácter exógeno y hasta cierto punto paternalista, con fuerte dependencia institucional del Estado o de la Iglesia. En todo caso, tales organizaciones suelen darse en torno a la solución de un problema concreto, generalmente vinculado a demandas de bienes de urbanización, y desaparecer con relativa rapidez.

Este recuento nos muestra un cuadro general de retroceso de las diversas formas de organizacion social y, por ende, de progresiva atomización, que guardaría relación con niveles de heterogeneidad estructural cada vez mayores. Al mismo tiempo, es posible que en ciertos segmentos especializados y delimitados se fortalezcan algunas organizaciones que actúan aisladamente y con una fuerte orientación corporativa de carácter defensivo.

\section{La organlzaclón política y la representaclón}

La imagen actual de una sociedad que acentúa su heterogeneidad estructural y su atomización se enmarca en una situación de representación política al parecer ampliada por el generalizado proceso de democratización que hizo retroceder la ola autoritaria de los ańos setenta. Como se ha dicho muchas veces, este proceso de democratización tuvo lugar en el período de severa crisis económica de los años ochenta, contradiciendo las viejas tesis de que el "momento político" viene después del "momento económico" de crecimiento y del "momento social" de distribución. La ocasión no parecía propicia, puesto que las libertades democráticas y la participación política permitirían dar expresión a las frustraciones y descontentos causados por la difícil situación, y el proceso de transformación de la estructura de estratificación no sólo generaba heterogeneidad y atomización, sino que lo hacía en un clima de polarización social, con un corte cada vez más nítido entre los que tenían y los que no tenían participación en el producto social del sector dinámico de la economía.

En estas circunstancias cabía imaginar que los mecanismos de la democracia política permitirían que los sectores postergados expresaran su demanda de mayor equilibrio social, y que esto podría dar origen a formas de articulación política que reemplazarían a las deterioradas organizaciones sociales.

Sin embargo, como señala Offe (1988), la democracia representativa, a través del sistema de partidos competitivos, ha eliminado la posibilidad de que estos partidos expresen el conflicto global: al tratar de captar al votante indeciso o de otro partido, tienden cada 
vez más a asemejarse en sus planteamientos, hasta eliminar toda diferencia significativa. Tal situación, sin embargo, no fue común en América Latina, debido al fuerte peso de algunas personalidades, al marcado tinte ideológico de algunas agrupaciones políticas y a la debilidad, salvo algunas excepciones, del sistema de partidos en la región.

El proceso de democratización de los años ochenta exhibe la impronta de la modernización política, que conduce a la especialización de esta actividad y la separa del sentido de representación sectorial de intereses sociales. Ese había sido su sentido original desde el inicio del moderno sistema partidario en torno a la creación de partidos de trabajadores o socialistas en el siglo XIX europeo (Cerroni, 1971), lo que no había dejado de tener influencia en la región latinoamericana desde comienzos de su industrialización.

La modernización política en el reciente proceso democratizador estuvo condicionada por dos hechos decisivos. Uno de ellos fue el cambio en la estructura social a que nos hemos referido, que debilitó las posibilidades de generalizar intereses y de organizarse socialmente, y limitó la capacidad de proyectar esas posiciones al ámbito político. El otro hecho fue la crisis y aparente colapso del socialismo, que ha privado a los sectores populares de una alternativa radical al esquema vigente y ha dejado al sistema partidario sin su principal punto de referencia.

Ambos hechos incidieron muy directamente en la transformación del sistema de partidos, los que muy pronto comenzaron a perder la representación sectorial que historicamente habían asumido. Esto, unido a la debilidad crónica del sistema partidario en varios países de la región, generó muy pronto los efectos señalados por Offe. A lo anterior se añadió una gran autonomía de supuestos representantes políticos, especialmente del más alto nivel, que viraban totalmente en el desempefio de sus cargos.

Ahora bien, en este cuadro la posibilidad de representación política de intereses se ha tornado prácticamente nula, en especial para los grupos más marginados y sumidos en una creciente atomización. A la vez han aumentado las posibilidades de que la clase política manipule a las masas, generando tensiones e inestabilidades, aunque estas se den dentro de una misma propuesta política y social.

Es aún demasiado pronto como para hacer vaticinios respecto del curso probable del proceso. No obstante, la tendencia pareciera ser la de garantizar la exclusión por un sistema político que se centra cada vez más en sí mismo. Dadas las condiciones descritas, es probable que la apatía suceda a la esperanzada participación en sistemas políticos con formas democráticas. Sin embargo, las condiciones sociales descritas dan pie a varias opciones, entre las cuales no se puede descartar la emergencia de algún tipo de populismo u otra alternativa al régimen democrático, si éste no logra desarrollar mecanismos de representación social y política concordantes con los profundos cambios estructurales que están en curso.

\section{Bibliografia}

Castillo, Mario y Claudio Cortellese (1988): La pequeña y mediana industria en el desarrollo de América Latina, Revista de la CEPAL, N 34 (LC/G. 1521-P), Santiago de Chile, abril,

CEPAL (1989): Transformación ocupacional y crisis social en América Latina, Santiago de Chile, diciembre. Publicación de las Naciones Unidas, $\mathrm{N}^{\circ}$ de venta S.90.II.G.3.

(1991): Panorama Social de América Latina (LC/G. 1688), Santiago de Chile, 31 de octubre.

Cerroni, U. (1971): Para una teoría del partido político, Teoría marxista del partido politico, Argentina, Ediciones Pasado y Presente.

CIDU (Centro de Desarrollo Urbano y Regional) Equipo de Estudios Poblacionales (1972): Reivindicación utbana y lucha política: los campamentos de pobladores en Santiago de Chile, EURE, vol. II, $\mathrm{N}^{\circ}$ 6, Santiago de Chile, Universidad Católica de Chile, noviembre.

De Oliveira, Francisco (1989): Innovaciones en políticas economico-sociales: el caso de Brasil, Consejo Latinoamericano de Ciencias Sociales (CLACSO), ¿Hacia un nuevo orden estatal de América Latina? Los actores socioeconómicos det ajuste estructural, vol.4, Buenos Aires.
Fajnzylber, Fernando (1983): La industrialización trunca de América Latina, México, D.F., Editorial Nueva Imagen, S.A.l Centro de Economía Transnacional (CET).

Germani, G. (1960): Politica e Massa, Rio de Janeiro, Universidade Federal de Minas Gerais, Faculdade de Dereito.

Gomes, Gerson y Antonio Pérez (1979): El proceso de modernizanción de la agricultura latinoamericana, Revista de la CEPAL, $\mathrm{N}^{\circ}$ 8. Santiago de Chile, agosto. Publicación de las Naciones Unidas, $\mathbb{N}^{\circ}$ de venta S.79.II.G.4.

Kaztman, Rubén (1984): Las transformaciones sectoriales del empleo en América Latina, Revista de la CEPAL, $\mathrm{N}^{\circ} 24$, Santia go de Chile, diciembre. Publicación de las Naciones Unidas, $\mathrm{N}^{\circ}$ de venta S.84.II.G.5.

López Cordovez, Luis (1982): Agricultura y alimentación. Evolución y transformaciones más recientes en América Latina, Revista de la CEPALL, N ${ }^{\circ} 16$, Santiago de Chile, abril. Publicación de las Naciones Unidas, $\mathrm{N}^{a}$ de venta S.82.II.G. 2

Medina Echavarría, José (1964): Consideraciones sociologicas sobre el desarrollo econ6mico, Buenos Aires, Solar/Editorial Hachette, S.A.

Mitó, Carmen y Daniel Rodríguez (1982): Capitalismo y pobla- 
ción en el agrolatinoamericano. Tendencias y problemas recientes. Revista de la CEPAL, $\mathrm{N}^{\circ} 16$, Santiago de Chile, abril. Publicactón de las Naciones Unidas. $N^{0}$ de venta S.82.II.G.2.

Offe, C. (1988): Partidos políticos y nuevos movimientos sociales, Madrid, Editorial Sistema.

Pinto, Anf́bal (1984): Metropolización y terciarización: malformaciones estructurales en el desarrollo latinoamericano, Revista de la CEPAL, $\mathrm{N}^{\circ} 24$, Santiago de Chile, diciembre. Publicación de las Naciones Unidas, $\mathbf{N}^{\circ}$ de venta S.84.II.G.5.

PREALC (Programa Regional del Empleo para América Latina y el Caribe) (1987): Desarticulación sacial en la periferia latinoamericana, Documento de trabajo, $\mathrm{N}^{a} 313$, Santiago de Chile, Oflcina Internacional del Trabajo (OIT).

(1988a): La evolución del mercado laboral entre 1980 y 1987, Documento de trabajo, $\mathrm{N}^{\circ} 328$, Santiago de Chile, OIT.

(1988b): Política económica y actores sociales, Santiago de Chile, OIT, mimeo.

Prieto, Francisco J. (1986): Los servicios: un vínculo inquietante entre América Latina y la economía mundial, Revista de lo CEPAL, $\mathrm{N}^{\mathrm{s}} 30$ (LC/G. 1441), Santiago de Chile, diciembre.
Przeworski, A. (1983): Compromiso de clase y Estado: Europa Occidental y América Latina, Norbert Lechner (ed.): Estado y Polftica en América Latina, México, D.F., Editorial Siglo XXI.

Rama, Germán y Enzo Faletto (1986): Sociedades dependientes y crisis en América Latina: los desafíos de la transformación político-social, Germán Rama (comp.), Escenarios políticos $y$ sociales del desarrollo latinoamericano, Buenos Aires, Editorial Universitaria de Buenos Aires (EUDEBA)/Naciones Unidas.

Tokman, Victor (1979): Dinámica de mercado de trabajo urbano; el sector informal urbano en América Latina, Fuerza de trabajo y movimiento laboral en América Latina, Kaztman, Reyes (Comp.), México, D.F. Colegio de México.

Touraine, Alain (1989): América Latina politica y sociedad, Madrid, Espasa-CALPE, S.A.

Weffort, F. (1970): Clases populares y desarrollo social, Santiago de Chile, Escuela Latinoamericana de Sociología (ELAS).

Wolfe, Marshall (1990): Las estructuras sociales y la democracia en los años noventa, Revista de la CEPAL, $\mathrm{N}^{\circ} 40$ (LC/G. 1613-P), Santiago de Chile, abril. 